\title{
Long-term follow-up and sudden unexpected death in Gaucher disease type 3 in Egypt OPEN
}

Magy Abdelwahab, MD, $\mathrm{PhD}$

Derek Blankenship, PhD Raphael Schiffmann, MD, MHSc

Correspondence to Dr. Schiffmann: Raphael.schiffmann@ baylorhealth.edu or Dr. Abdelwahab: magywahab@yahoo.com

Supplemental data at Neurology.org/ng

\section{ABSTRACT}

Objective: To describe the long-term follow-up and distinct phenotype of a large cohort of patients with Gaucher disease type 3 on enzyme replacement therapy (ERT) in Egypt.

Methods: A prospective cohort study of 78 patients on ERT who were followed for up to 9 years with yearly evaluations that included EEG and cognitive testing.

Results: Of the patients, 73\% were homozygous for the L444P GBA1 mutation; all but 7 were neurologically symptomatic. Supranuclear gaze palsy with variable but stable cognitive function was present in $91 \%$ of patients. Convergent strabismus and bulbar dysfunction were noted in $22 \%$ and $37 \%$, respectively. Features of oppositional defiant disorder were present in 54\% of patients. Twenty-three patients (30\%) developed seizures while on ERT for 1-9 years. Of those, 12 patients (15\%) died suddenly and unexpectedly at a mean age of $6.7 \pm 5.0$ years (range 1.518). Sudden death was usually associated with a seizure disorder or a terminal seizure, but 7 of 12 patients had a preceding normal EEG. An additional 11\% had background slowing or epileptogenic activity on EEG without clinical seizures. There were 3 familial cases of sudden unexpected death.

Conclusions: Despite having the most common GBA1 genotype known to be associated with neuronopathic Gaucher disease, patients with Gaucher disease type 3 in Egypt have a phenotype and a clinical outcome on ERT that are very different from those observed in other populations. Identifying putative modifying genes of this ethnic group is likely to lead to better therapy for neuronopathic Gaucher disease generally. Neurol Genet 2016;2:e55; doi: 10.1212/ NXG.0000000000000055

\section{GLOSSARY}

ERT = enzyme replacement therapy; SUDEP = sudden unexpected death in epilepsy.

Gaucher disease is the most common autosomal recessive lysosomal storage disease and is caused by a deficiency of glucocerebrosidase due to pathogenic variants of the $G B A 1$ gene. ${ }^{1}$ Gaucher disease type 1, the nonneuronopathic form, has an incidence of about 1 in 40,000-60,000 in the general population and 1 in 500-1,000 among Ashkenazi Jews. ${ }^{2}$ Patients with Gaucher disease type 3 (also called chronic neuronopathic Gaucher disease) constitute about 5\% of the population of patients with Gaucher disease in the United States and in Europe, with an estimated incidence of about 1:100,000. ${ }^{3}$ However, recent reports suggest that this form of Gaucher disease predominates in countries such as China, Korea, and Egypt. ${ }^{4-8}$ Gaucher disease type 3 presents most often with severe systemic disease and supranuclear gaze palsy and often with a cognitive deficit. ${ }^{9,10}$ Rarely, these patients may present with myoclonus or seizures that are often associated with mild systemic disease. ${ }^{11}$ Before the advent of enzyme replacement therapy (ERT), pulmonary infiltrates and esophageal varices associated with liver cirrhosis were common. ${ }^{9}$ ERT has no reported direct effect on the neurologic aspects of the disease. ${ }^{3,10,12,13}$

\footnotetext{
From the Department of Pediatric Hematology (M.A.), Cairo University Pediatric Hospital, Egypt; and Department of Biostatistics (D.B.) and Institute of Metabolic Disease (R.S.), Baylor Research Institute, Dallas, TX.

Funding information and disclosures are provided at the end of the article. Go to Neurology.org/ng for full disclosure forms. The Article Processing Charge was paid by the authors.

This is an open access article distributed under the terms of the Creative Commons Attribution-NonCommercial-NoDerivatives License 4.0 (CC BY-NC-ND), which permits downloading and sharing the work provided it is properly cited. The work cannot be changed in any way or used commercially.
} 
Therefore, long-term ERT allows for study of the intrinsic neurologic natural history of Gaucher disease type 3.

Here we describe the long-term follow-up of Gaucher disease in patients in Egypt who almost all have a single (and the most common) neuronopathic GBA1 genotype. ${ }^{1}$ We show that, for an unknown reason, their phenotype and clinical outcome are very different from those described in similar patients in other countries.

METHODS Standard protocol approvals, registrations, and patient consents. Patients were followed prospectively on the International Collaborative Gaucher Group Gaucher Registry, clinicaltrials.gov study number NCT00358943, and enrolled in the Neurological Outcomes Subregistry. All legal guardians of patients gave their written informed consent per protocol. In addition, all studies used standard of care for neuronopathic Gaucher disease.

All patients with Gaucher disease type 3 and neurologically asymptomatic patients with the L444P/L444P GBA1 genotype (c.1448T $>$ C) who were on ERT were included in this study. All patients were diagnosed by glucocerebrosidase deficiency followed by GBA1 genotyping. Analysis for common mutations was performed by PCR followed by Sanger sequencing. Full sequencing of the $G B A$ gene was performed as previously described. ${ }^{14,15}$ In addition, for some patients, a strip hybridization-based assay for Gaucher disease was used for the detection of 8 commonly reported mutations in the GBA gene (c.84dupG (84GG), c.115+1G $>$ A (IVS2+1G $>A$ ), c.1226A $>$ G (p.N370S), c.1297G $>$ T (p.V394L), c.1342G $>$ C (p.D409H), c.1448T >C (p.L444P), c.1504C >T (p.R463C), and c.1604G $>$ A (p.R496H)) and 2 recombinant alleles (RecNci-l and RecTL) according to manufacturer's protocol (Viennalab Diagnostics, Vienna, Austria). However, GBA1 genotyping was not performed in some patients (designated as unknown in tables e1 and e-2 at Neurology.org/ng).

Neurologic evaluation included performing 21-channel standard EEG and IQ testing when the patient's overall health was sufficiently improved to permit meaningful measurement. Assessment varied according to age; Vineland Adaptive Behavioral Scale was used for children $<4$ years and Wechsler intelligence scales were used for preschool, school-age, and adult groups. Neurocognitive impairment is mild if IQ is 55-70, moderate if IQ is $35-55$, and severe if IQ is $<35$.

ERT dose ranged from 20 to $60 \mathrm{IU} / \mathrm{kg}$ of body weight every 2 weeks. Some patients were given a trial of higher ERT doses when possible to better control their symptoms (table e-1).

Statistical analysis. Summary statistics for continuous and categorical variables are reported with mean $( \pm S D)$ and percentages, respectively. Time-to-event analyses were conducted using Kaplan-Meier survival curves with Hall-Wellner 95\% confidence intervals.

RESULTS Patient description. A total of 78 patients were followed over 1-9 years. Their mean \pm SD age when last examined was $9.5 \pm 5.5$ years (range, 1.5-22.5). Twenty-three patients developed seizures (table e-1), 9 patients had EEG abnormalities without clinical seizures (table e-1), and 46 patients had no EEG abnormality or seizures (table e-2).

GBA1 genotype and phenotype. Patients, their genotype, and clinical characteristics are presented in tables e-1 and e-2. In the group with seizures, all but 3 patients were L444P homozygous: 1 patient was $\mathrm{D} 409 \mathrm{H}$ homozygous, and the mutations in the other 2 were unknown. In the group without seizures and with normal EEG, 2 patients with D409H/D409H had aortic root and valvular calcifications and regurgitation, whereas 1 patient (patient 6) had a newly observed anomaly consisting of ectatic proximal coronaries. These patients had increased reflectivity of the cornea and asymptomatic hydrocephalus. In the group with EEG abnormalities, 6 patients were L444P homozygous and 3 were unknown. Among those with no EEG abnormalities or seizures, 31 patients were L444P homozygous and the genotype in 9 was unknown. Eighty percent of all patients were homozygous for L444P. Virtually all patients had consanguineous parents. There was considerable intrafamilial heterogeneity, and siblings often had discordant neurologic and systemic disease severity (tables e-1 and e-2).

Seven patients, all in the normal EEG and no seizures group, had no neurologic abnormalities on clinical examination, including normal horizontal saccades. Six of them were homozygous for L444P and 1 was $\mathrm{L} 444 \mathrm{P} / \mathrm{D} 409 \mathrm{H} ; 3$ patients had a splenectomy at a very early age. The other 71 patients all had supranuclear gaze palsy in isolation or in combination with variable developmental delay but often had improved motor skills over time. Patients with seizures (table e-1) had lower cognitive function than those with no seizures and normal EEG (table e-2). If one imputes an IQ of 100 to those with clearly normal cognitive function, the Full-Scale IQ of the former group was $68 \pm 15$ and that of the latter group was $85 \pm 13(p<0.0001)$. Our patients tended to remain cognitively stable over the years. Convergent strabismus was noted in $22 \%$ overall (11\% without and $37 \%$ with seizures or EEG abnormalities). Bulbar dysfunction was reported in $37 \%$ overall $(28 \%$ without and $50 \%$ with seizures or EEG abnormalities) (tables e-1 and e-2). Features of oppositional defiant disorder ${ }^{16}$ were observed in $54 \%$ overall ( $48 \%$ without and $62 \%$ with EEG abnormalities). EEG abnormalities consisted of a persistent generalized slow and disorganized background, often seen in diffuse encephalopathies (table e-1). EEG abnormality was not always associated with clinical seizures; on the other hand, no epileptogenic activity was detected with surface EEG in some patients with seizures. Seizures were reported in about $30 \%$ of patients with Gaucher disease type 3 who were on ERT (table e-1), and their cumulative incidence is 
presented in figure 1. Seizures were focal, focal with secondary generalization, or generalized at onset. Six patients had their first seizures just before sudden death. Patients with a chronic seizure disorder were treated with valproic acid at a dose of up to $60 \mathrm{mg} / \mathrm{kg} /$ day, with variable results (table e-1).

Patient outcome. Twelve patients died unexpectedly at a mean age of $6.7 \pm 5.0$ years (range $1.5-18$ ). The cumulative incidence of sudden death in patients with seizures, in those with seizures and EEG abnormalities, and in the overall study population is presented in figure 2. Most patients died after a seizure. Of note, 7 of the 12 patients who died suddenly had a preceding normal EEG (table e-1). Patients were followed for a total of 476 years, which is an incidence of sudden death of 25 per 1,000 patient-years in this population of patients with Gaucher disease. There was no clear relationship between sudden unexpected death and the severity of the systemic disease, ERT dose, or cognitive level. There were 3 cases in which sudden unexpected death occurred in 2 affected siblings in a family_patients 6 and 7; the identical twin and cousin of patient 21 died suddenly with seizures; and patient 22 and his sibling both died suddenly after seizure.

DISCUSSION Here we present a large and genetically homogeneous patient cohort with Gaucher disease type 3, most of whom (about 80\%) had the common neuronopathic Gaucher genotype L444P/L444P. This cohort shows the entire clinical spectrum of this genotype-from normal neurologic phenotype to severe neurologic manifestations. We included only patients on ERT in this

Figure 1 Cumulative incidence of seizures in 78 patients with Gaucher disease type 3 receiving enzyme replacement therapy

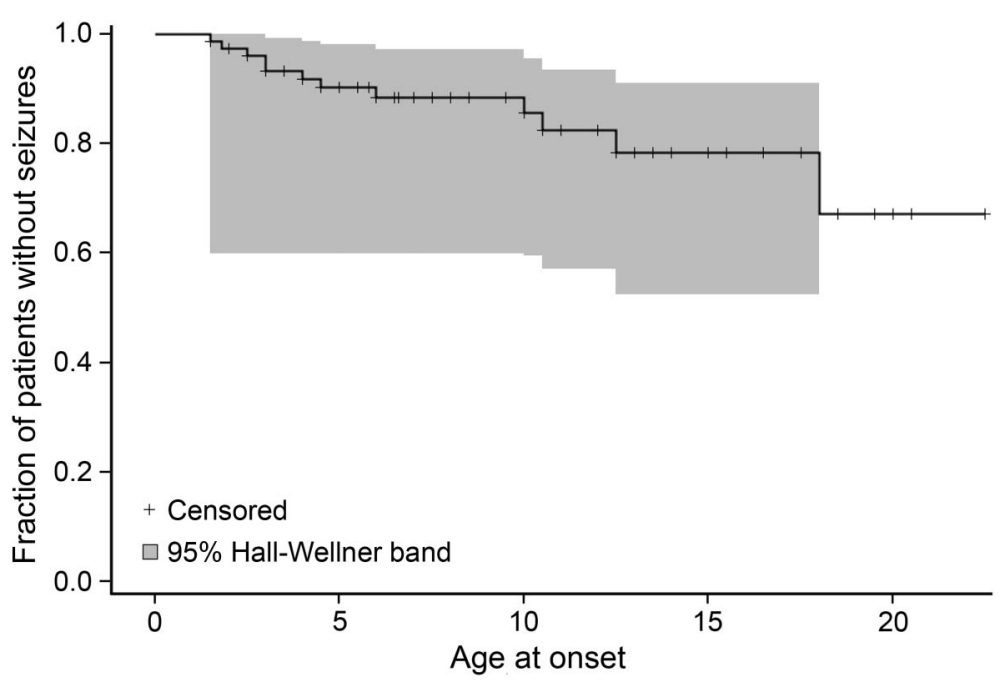

The shaded area represents the $95 \%$ confidence interval. study because general health and cognitive performance in patients with Gaucher disease type 3 are known to be influenced by the visceral disease. ${ }^{3,13}$ Therefore, the neurologic outcome of patients with Gaucher disease type 3 on long-term ERT reflects only their intrinsic cerebral dysfunction. The phenotype observed in our patients consisted of marked behavioral abnormalities; common bulbar dysfunction (dysarthria, dysphagia, or stridor); epilepsy; and frequent sudden unexpected death, usually with epilepsy or an isolated seizure, in the face of stable cognitive function in most patients. Remarkably, their phenotype was more severe and different from that described for the same genotype in other countries. ${ }^{13,17-19}$ It should be noted that $31 \%$ of patients in the study analyzing the Neurological Outcomes Subregistry of the International Collaborative Gaucher Group Gaucher Registry as of June 1, 2007, were from Egypt, but their phenotype was not specifically described. ${ }^{19}$ Patients with Gaucher disease type 3 in China and Japan seem to have more severe neurologic disease than patients in Europe and the United States. ${ }^{6,7}$ However, none of these studies have described sudden death, even in patients receiving long-term ERT. Behavioral problems have not been described in patients with Gaucher disease type 3. A 17-year-old Arab Israeli female patient with the L444P/L444P genotype developed epilepsy that devolved into myoclonic seizures and a more rapid cognitive decline. ${ }^{20}$

The causes of death of our patients are unknown, but in most cases death occurred shortly after an epileptic seizure. In these cases, sudden unexpected death in epilepsy (SUDEP) can be invoked. ${ }^{21,22}$ The incidence of SUDEP in our study population is much higher than that described in various epilepsy populations (0.35-9.3 per 1,000 person-years). ${ }^{23,24}$

The epileptic seizures in many cases were phenotypically partial complex, with possible temporal lobe epileptogenic foci in some patients. Involvement of the temporal lobes in neuronopathic Gaucher disease is not surprising because a specific pattern of hippocampal neuropathologic abnormalities has been described. ${ }^{25}$ Our data suggest that epilepsy in Gaucher disease type 3 is associated with a risk for sudden unexpected death, but a normal EEG does not preclude sudden death. In the general population, the incidence of SUDEP is inversely related to remission of epilepsy. ${ }^{23}$ The lowest incidence of SUDEP is in patients with well-controlled epilepsy or patients in remission. ${ }^{26}$ Therefore, seizure control is likely to be the most direct way of preventing SUDEP in this population of patients with Gaucher disease. It remains to be seen whether 
Figure 2 Cumulative incidence of sudden death

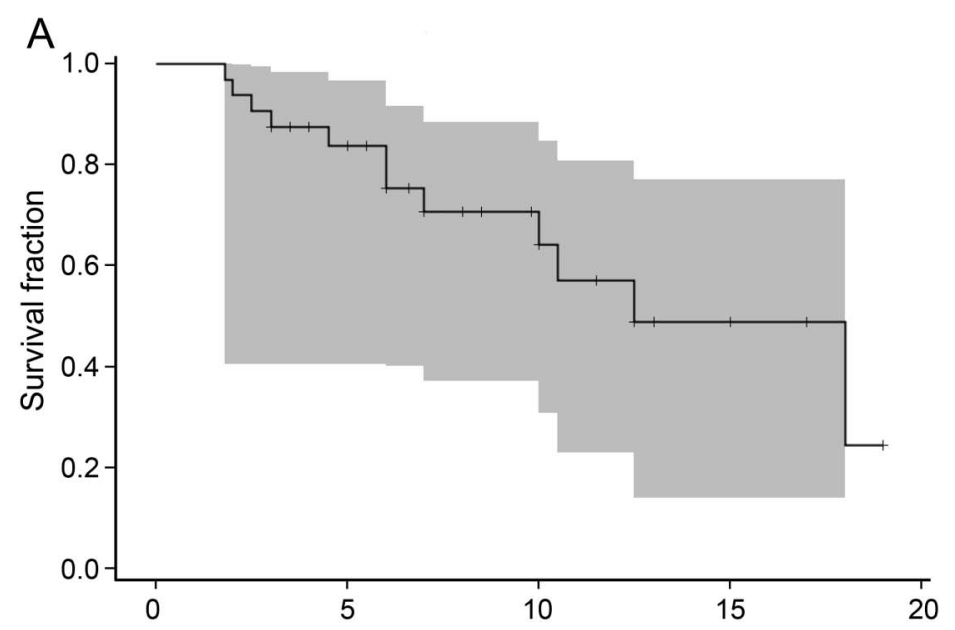

B
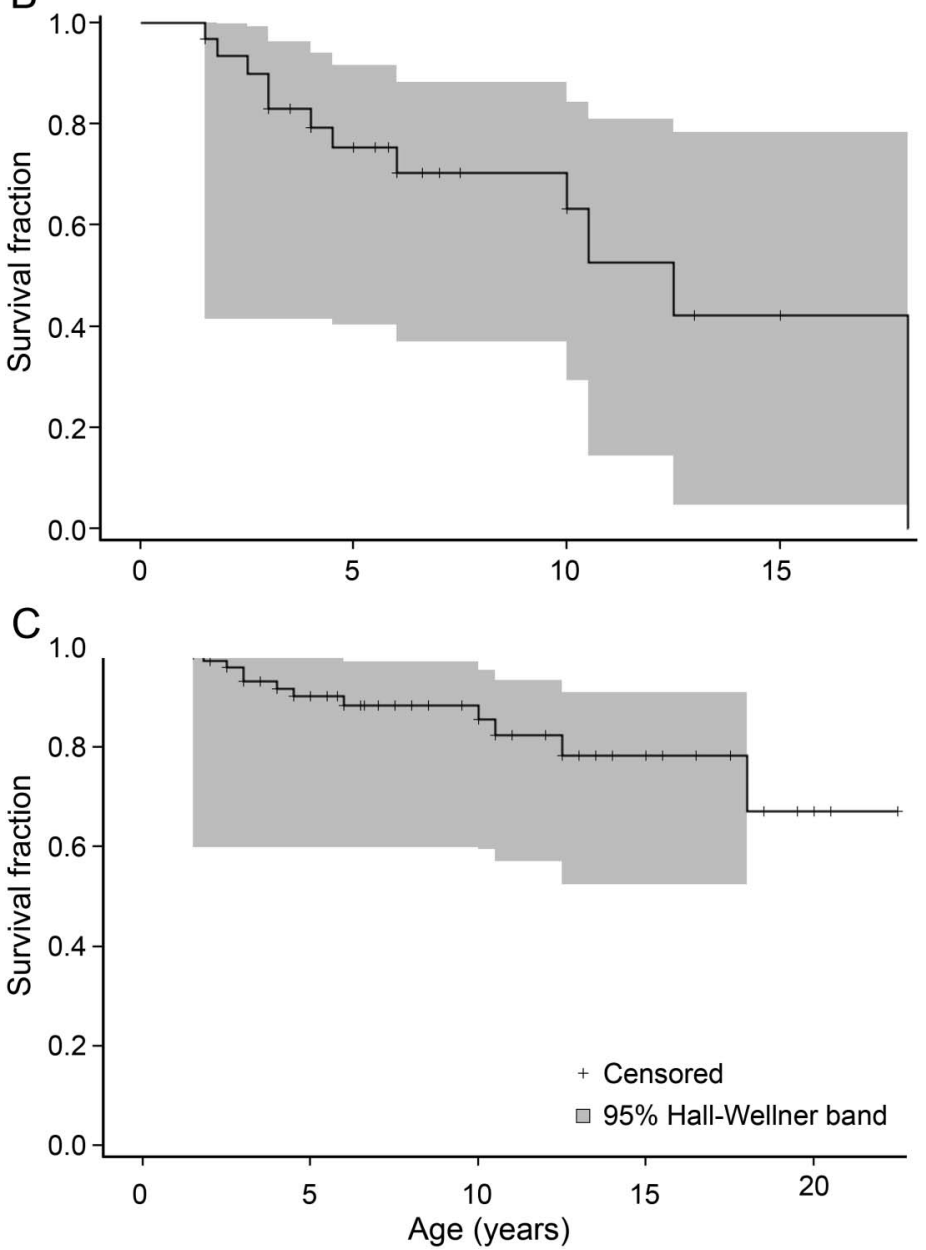

Cumulative incidence of sudden death (A) in patients with seizures, $(B)$ in those with seizures and EEG abnormalities, and (C) in the overall study population. The shaded area represents the $95 \%$ confidence interval.

prophylactic use of certain antiepileptic medications can decrease the likelihood of SUDEP in this patient population.

The reason for such a unique Gaucher disease type 3 phenotype, which includes behavioral abnormalities, frequent bulbar dysfunction, epilepsy, and sudden unexpected death, in patients in Egypt is unknown. It is likely that modifier gene variants common in this population contribute to this phenotype. These may include ion channels that are directly or indirectly influenced by cellular levels of glucosylceramide. ${ }^{27}$ Increased sensitivity of hippocampal neurons to glutamate-induced neurotoxicity has been described. ${ }^{28}$ The higher the level of glucosylceramide in neurons, the greater the toxicity. ${ }^{28}$ Therefore, certain glutamate receptors may play a role in the phenotypic expression of neuronopathic Gaucher disease. Defective calcium homeostasis mediated by overactivity of the ryanodine receptor that correlated with glucosylceramide levels was also described. ${ }^{29}$ The ryanodine receptor is particularly expressed in the most affected hippocampal areas, CA2-CA4. ${ }^{25}$ Therefore, this calcium receptor may also be a potential phenotype modulator in neuronopathic Gaucher disease. A yet-unidentified cardiovascular risk factor may be an important contributor to SUDEP in Egyptian patients with Gaucher disease type 3. ${ }^{30}$

The detailed clinical spectrum and long-term follow-up of Gaucher disease type 3 in Egypt presented here should be useful for the development and assessment of primary therapy for this disease and for identifying genetic modifiers. Such genetic variants may help identify the best antiepileptic medications or other medical interventions to either use or omit in this condition. It may also lead to using other disease-altering agents that are not currently under consideration.

\section{AUTHOR CONTRIBUTIONS}

M.A. recruited and studied the patients and gathered all data, interpreted and analyzed the data, and edited the manuscript. D.B. performed the statistical analysis and edited the manuscript. R.S. interpreted and analyzed the data and wrote the manuscript.

\section{ACKNOWLEDGMENT}

The authors thank Dr. Pramod Mistry, Yale University, for help with GBA1 sequencing; Dr. Khaled Eid for technical help; Dr. Mohamed Abd Elmonem, Cairo University, Egypt, for help with GBA1 genotyping; and Genzyme A Sanofi Company, Shire Plc, and the Hope project for providing ERT product.

\section{STUDY FUNDING}

The study received local standard of care hospital support.

\section{DISCLOSURE}

M.A. has received travel support and/or honoraria from Genzyme. D.B. reports no disclosures. R.S. has served on scientific advisory boards and received funding for travel and/or speaker honoraria from Protalix Biotherapeutics and Amicus Therapeutics; has applied for and/or holds patents for triheptanoin diet for adult polyglucosan body disease treatment, use of tetrahydrobiopterin as a marker and a therapeutic agent for Fabry disease, use of tetrahydrobiopterin as a marker and a therapeutic agent for Fabry disease (Europe), urinary triaosylceramide (gb3) as a marker of cardiac disease (Europe), and gene encoding a new TRP channel is mutated in mucolipidosis; has consulted for Gerson Lehrman Group Councils Guidepoint Global; has served on speakers' bureaus for Genzyme Corporation; and has received research support from Protalix Biotherapeutics, 
Amicus Therapeutics, and Baylor Research Foundation. Go to Neurology. org/ng for full disclosure forms.

Received August 9, 2015. Accepted in final form December 17, 2015.

\section{REFERENCES}

1. Grabowski GA, Petsko GA, Kolodny EH. Gaucher disease. In: Scriver AL, Beaudet W, Sly S, Valle D, eds. The Metabolic and Molecular Bases of Inherited Disease, 9th ed. New York: McGraw-Hill; 2006.

2. Grabowski GA, Horowitz M. Gaucher's disease: molecular, genetic and enzymological aspects. Baillieres Clin Haematol 1997;10:635-656.

3. Vellodi A, Tylki-Szymanska A, Davies EH, et al. Management of neuronopathic Gaucher disease: revised recommendations. J Inherit Metab Dis 2009;32:660-664.

4. El-Morsy Z, Khashaba MT, Soliman Oel S, Yahia S, ElHady DA. Glucosidase acid beta gene mutations in Egyptian children with Gaucher disease and relation to disease phenotypes. World J Pediatr 2011;7:326-330.

5. Jeong SY, Park SJ, Kim HJ. Clinical and genetic characteristics of Korean patients with Gaucher disease. Blood Cells Mol Dis 2011;46:11-14.

6. Tajima A, Yokoi T, Ariga M, et al. Clinical and genetic study of Japanese patients with type 3 Gaucher disease. Mol Genet Metab 2009;97:272-277.

7. Choy FY, Zhang W, Shi HP, et al. Gaucher disease among Chinese patients: review on genotype/phenotype correlation from 29 patients and identification of novel and rare alleles. Blood Cells Mol Dis 2007;38:287-293.

8. Wan L, Hsu CM, Tsai CH, Lee CC, Hwu WL, Tsai FJ. Mutation analysis of Gaucher disease patients in Taiwan: high prevalence of the RecNcil and L444P mutations. Blood Cells Mol Dis 2006;36:422-425.

9. Patterson MC, Horowitz M, Abel RB, et al. Isolated horizontal supranuclear gaze palsy as a marker of severe systemic involvement in Gaucher's disease. Neurology 1993; 43:1993-1997.

10. Schiffmann R, Heyes MP, Aerts JM, et al. Prospective study of neurological responses to treatment with macrophage-targeted glucocerebrosidase in patients with type 3 Gaucher's disease. Ann Neurol 1997;42: 613-621.

11. Frei KP, Schiffmann R. Myoclonus in Gaucher disease. Adv Neurol 2002;89:41-48.

12. Goker-Alpan O, Wiggs EA, Eblan MJ, et al. Cognitive outcome in treated patients with chronic neuronopathic Gaucher disease. J Pediatr 2008;153:89-94.

13. Altarescu G, Hill S, Wiggs E, et al. The efficacy of enzyme replacement therapy in patients with chronic neuronopathic Gaucher's disease. J Pediatr 2001;138:539-547.

14. El-Beshlawy A, Ragab L, Youssry I, et al. Enzyme replacement therapy and bony changes in Egyptian paediatric Gaucher disease patients. J Inherit Metab Dis 2006;29: 92-98.

15. Tayebi N, Stern H, Dymarskaia I, Herman J, Sidransky E. 55-base pair deletion in certain patients with Gaucher disease complicates screening for common Gaucher alleles. Am J Med Genet 1996;66:316-319.

16. Herzhoff K, Tackett JL. Subfactors of oppositional defiant disorder: converging evidence from structural and latent class analyses. J Child Psychol Psychiatry Epub 2015 Apr 22.

17. Davies EH, Erikson A, Collin-Histed T, Mengel E, TylkiSzymanska A, Vellodi A. Outcome of type III Gaucher disease on enzyme replacement therapy: review of 55 cases. J Inherit Metab Dis 2007;30:935-942.

18. Davies EH, Mengel E, Tylki-Szymanska A, Kleinotiene G, Reinke J, Vellodi A. Four-year followup of chronic neuronopathic Gaucher disease in Europeans using a modified severity scoring tool. J Inherit Metab Dis 2011;34:1053-1059.

19. Tylki-Szymanska A, Vellodi A, El-Beshlawy A, Cole JA, Kolodny E. Neuronopathic Gaucher disease: demographic and clinical features of 131 patients enrolled in the International Collaborative Gaucher Group Neurological Outcomes Subregistry. J Inherit Metab Dis 2010;33:339-346.

20. Elstein D, Abrahamov A, Altarescu G, Zimran A. Evolving features in type 3 Gaucher disease on long-term enzyme replacement therapy. Blood Cells Mol Dis 2013;50:140.

21. Goldman AM. Mechanisms of sudden unexplained death in epilepsy. Curr Opin Neurol 2015;28:166-174.

22. Nashef L, So EL, Ryvlin P, Tomson T. Unifying the definitions of sudden unexpected death in epilepsy. Epilepsia 2012;53:227-233.

23. Dlouhy BJ, Gehlbach BK, Richerson GB. Sudden unexpected death in epilepsy: basic mechanisms and clinical implications for prevention. J Neurol Neurosurg Psychiatry Epub 2015 Jun 2.

24. Thurman DJ, Hesdorffer DC, French JA. Sudden unexpected death in epilepsy: assessing the public health burden. Epilepsia 2014;55:1479-1485.

25. Wong K, Sidransky E, Verma A, et al. Neuropathology provides clues to the pathophysiology of Gaucher disease. Mol Genet Metab 2004;82:192-207.

26. Ryvlin P, Cucherat M, Rheims S. Risk of sudden unexpected death in epilepsy in patients given adjunctive antiepileptic treatment for refractory seizures: a meta-analysis of placebo-controlled randomised trials. Lancet Neurol 2011;10:961-968.

27. Vitner EB, Futerman AH. Neuronal forms of Gaucher disease. Handb Exp Pharmacol 2013:405-419.

28. Pelled D, Shogomori H, Futerman AH. The increased sensitivity of neurons with elevated glucocerebroside to neurotoxic agents can be reversed by imiglucerase. J Inherit Metab Dis 2000;23:175-184.

29. Pelled D, Trajkovic-Bodennec S, Lloyd-Evans E, Sidransky E, Schiffmann R, Futerman AH. Enhanced calcium release in the acute neuronopathic form of Gaucher disease. Neurobiol Dis 2005;18:83-88.

30. Lamberts RJ, Blom MT, Wassenaar M, et al. Sudden cardiac arrest in people with epilepsy in the community: circumstances and risk factors. Neurology 2015;85: 212-218. 


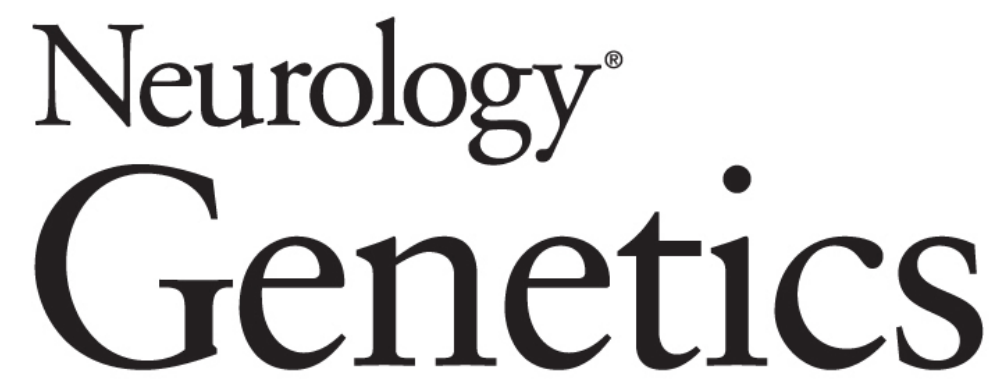

Long-term follow-up and sudden unexpected death in Gaucher disease type 3 in Egypt Magy Abdelwahab, Derek Blankenship and Raphael Schiffmann Neurol Genet 2016;2;

DOI 10.1212/NXG.0000000000000055

This information is current as of February 25, 2016

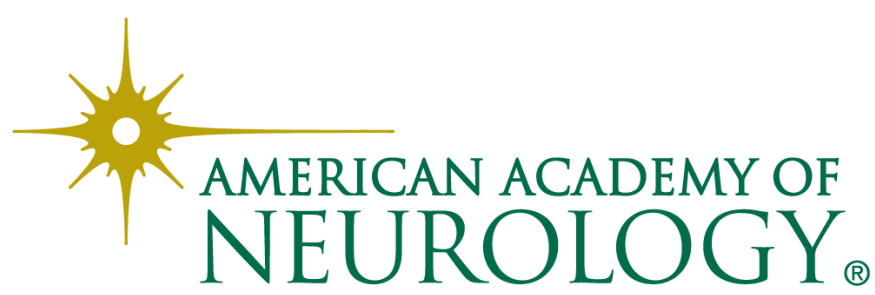




\section{Updated Information \& Services}

\section{Supplementary Material}

\section{References}

Citations

Subspecialty Collections

Permissions \& Licensing

\section{Reprints}

including high resolution figures, can be found at: http://ng.neurology.org/content/2/2/e55.full.html

Supplementary material can be found at: http://ng.neurology.org/content/suppl/2016/02/25/2.2.e55.DC1

This article cites 26 articles, 0 of which you can access for free at: http://ng.neurology.org/content/2/2/e55.full.html\#\#ref-list-1

This article has been cited by 1 HighWire-hosted articles: http://ng.neurology.org/content/2/2/e55.full.html\#\#otherarticles

This article, along with others on similar topics, appears in the following collection(s):

All Epilepsy/Seizures

http://ng.neurology.org//cgi/collection/all_epilepsy_seizures

\section{All Genetics}

http://ng.neurology.org//cgi/collection/all_genetics

Lipidoses

http://ng.neurology.org//cgi/collection/lipidoses

Metabolic disease (inherited)

http://ng.neurology.org//cgi/collection/metabolic_disease_inherited

Natural history studies (prognosis)

http://ng.neurology.org//cgi/collection/natural_history_studies_prognos is

Information about reproducing this article in parts (figures,tables) or in its entirety can be found online at:

http://ng.neurology.org/misc/about.xhtml\#permissions

Information about ordering reprints can be found online: http://ng.neurology.org/misc/addir.xhtml\#reprintsus

Neurol Genet is an official journal of the American Academy of Neurology. Published since April 2015, it is an open-access, online-only, continuous publication journal. Copyright ( 2016 American Academy of Neurology. All rights reserved. Online ISSN: 2376-7839.

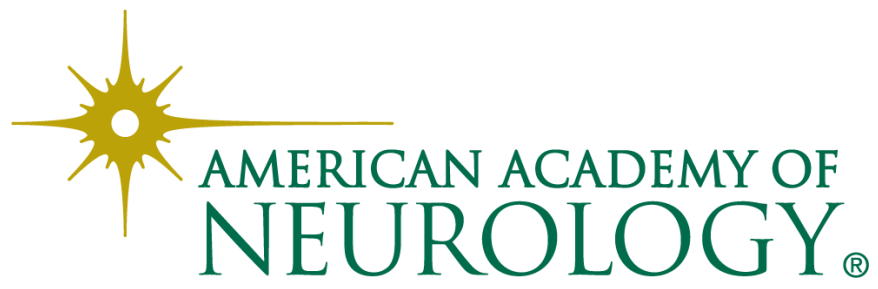

